\title{
Necrotizing Fasciitis: A Review of Outcomes from Necrotizing Fasciitis in Regional Far North Queensland
}

\author{
Veral Vishnoi", Heng Chin Chiam and Paul Liebenberg
}

Department of Surgery, Cairns Hospital, Australia

"Corresponding author: Veral Vishnoi, Department of Surgery, Cairns Hospital, Australia, E-mail: veralvishnoi1612@hotmail.com

Received date: September 08, 2018; Accepted date: October 08, 2018; Published date: October 12, 2018

Copyright: ( 2018 Vishnoi V, et al. This is an open-access article distributed under the terms of the Creative Commons Attribution License; which permits unrestricted use; distribution; and reproduction in any medium; provided the original author and source are credited.

\begin{abstract}
Purpose: This 12-year audit aimed to review the number and outcomes of all cases of Necrotizing fasciitis (NF) admitted to CAIRNS BASE HOSPITAL (CBH) from 2001 to 2013.

Methodology: A retrospective chart review of cases between 2000 and 2013 was carried out using a standard proforma to document patient characteristics, management and outcomes.

Results: 66 patients were identified. Of these, $64 \%$ were male and the average age was 54 years. $50 \%$ of patients identified as either Aboriginal or Torres Strait islander. $74 \%$ required an intensive care admission and the overall mortality was $18 \%$. The strongest identifiable risk factor was diabetes mellitus (DM), present in $60 \%$ of the cohort. DM was a predictor of mortality, with the data suggesting a tenfold increase in chance of death from NF $(p=0.031)$. An isolated infection with staphylococcus had a higher mortality in comparison to polymicrobial $(p=0.015)$ or streptococcus $(p=0.041)$. The presence of acute renal failure was associated with a nine-fold increase in the likelihood of death $(p=0.002)$. Smoking, race, time to surgery, precipitating cause (i.e. spontaneous, post operation, trauma etc.) and location (leg, perineum, etc.) had no statistical impact on mortality.
\end{abstract}

Conclusion: Diabetes mellitus, primary staphylococcus infection and acute renal failure are strong predictors of mortality in NF. Race and time to surgery had no statistical impact in the overall mortality, which is a very relevant finding for a regional centre with a high indigenous population.

Keywords: Necrotising fasciitis; Tropical medicine; Remote medicine

\section{Introduction}

Necrotizing Soft-tissue infections (NTSI's) constitute a group of rare, but potentially lethal diseases [1]. They are usually caused by toxin-producing, virulent bacteria, and is characterized by widespread fascial necrosis with relative sparing of skin and underlying muscle [2]. It is often associated with severe systemic toxicity and is usually rapidly fatal unless promptly recognized and aggressively treated [3]. The current gold standard treatment involves urgent surgical debridement, intravenous antibiotics (consulting infectious disease teams were able) and supportive measures (often requiring intensive care admission) [4].

Cairns Base Hospital (CBH) serves as a secondary referral hospital and supplies community and specialist hospital services for Cairns and its immediate surroundings and is the major referral centre for Tropical North Queensland [5]. The hospital has 500 overnight beds. The Cairns and Hinterland Hospital and Health Service (HHS) covers an area of 142,000 square kilometres from Cardwell in the south to Mossman in the north and Croydon in the west [5]. The HHS serves a population of around 250,000 people. $\mathrm{CBH}$ also receives patients from as far north as Papua New Guinea via Thursday Island and the Torres Strait.

Tropical North Queensland is home to many native and ethnic groups. It also serves as a major referral centre for the Torres Strait Islands and Papa New Guinea, which brings with it, complex, challenging tropical medicine which includes necrotizing fasciitis. One of the biggest problems faced by Tropical North Queensland is the distance between major hospitals. Besides Cairns Base Hospital and Townsville teaching hospital, Tropical north Queensland's health care is provided by peripheral hospitals run by rural generalists.

These peripheral hospitals are an asset to the state where distance between major centres is so vast, however they are limited in their capabilities and resources. Surgical, anaesthetic, medical and obstetric emergencies can be dealt with temporarily, before more definitive management is required at a major centre such as Cairns base hospital. This becomes very relevant when discussing surgical emergencies such as necrotizing fasciitis. The purpose of this retrospective audit was to identify all the cases of necrotizing fasciitis managed in Cairns base hospital, to determine the overall outcomes of these patients, looking specifically at factors that are relevant to medicine in Far North Queensland. These factors included, race, comorbidities, time to surgery and causative organisms.

\section{Methods}

\section{Study location}

Cairns Base Hospital 
Citation: Vishnoi V, Chiam HC, Liebenberg P (2018) Necrotizing Fasciitis: A Review of Outcomes from Necrotizing Fasciitis in Regional Far North Queensland. J Trop Dis 6: 285. doi:10.4172/2329-891X.1000285

Page 2 of 6

\section{Ethics approval}

Human Research Ethics Committee, Cairns and Hinterland, Cape, Torres and Northern Peninsula Hospital and Health Service, dated 6 September 2012, HREC reference number: HREC/12/QCH/90-807 LR.

\section{Data collection}

Data was collected from retrospective chart analysis of all patients with discharge International Classification of Diseases 10 coding for necrotizing fasciitis between June 2002 and June 2013. 66 patients were identified during this search. Patients were only included in this analysis if they had histological or operative reports confirming necrotizing fasciitis.

Data collected included individual patient demographics (age, sex, co-morbidities, geographical location), investigations performed, treatment initiated (anti-microbial choice), time to surgery, operation reports, critical care involvement, length of stay, need for further operations and overall mortality.

\section{Data analysis}

Data were entered into Microsoft Excel and then subsequently analysed with IBM SPSS. Univariate and multi-variate logistical regressions were applied to the data in an attempt to identify correlations with demographics and disease process on the overall mortality.

\section{Results}

\section{Demographics and co-morbidities}

A total of 66 patients were identified in this retrospective review. 40 patients were male $(61 \%)$ and 26 were female $(39 \%)$. The median age was 54 (range 18-83). A total of 33 (50\%) patients identified as either Aboriginal or Torres Strait Islander (ATSI).

A total of 49 patients (78\%) required an intensive care admission. A total of 12 people died, resulting in a mortality of $18 \%$. Diabetes mellitus was present in 39 patients (60\%). Ischaemic heart disease, hypertension and chronic airway disease were also present in the majority of patients; however, this was more difficult to quantify due to subjective diagnosis with a lack of specialist input. A further 32 patients (48\%) were smokers. The demographics have been summarised in Table 1.

\begin{tabular}{|l|l|l|l|}
\hline & $\begin{array}{l}\text { Whole group } \\
(\mathbf{n = 6 6 )}\end{array}$ & $\begin{array}{l}\text { Survivors } \\
(\mathbf{n = 5 4})\end{array}$ & $\begin{array}{l}\text { Deceased } \\
(\mathbf{n}=12)\end{array}$ \\
\hline Age & $54(18-83)$ & $47(18-73)$ & $57(33-83)$ \\
\hline Gender & $40(61 \%)$ & $36(66 \%)$ & $4(33 \%)$ \\
\hline Male & $26(39 \%)$ & $18(33 \%)$ & $8(66 \%)$ \\
\hline Female & \multicolumn{3}{|l|}{} \\
\hline Race & $33(50 \%)$ & $29(54 \%)$ & $4(33 \%)$ \\
\hline ATSI & $20(30 \%)$ & $14(26 \%)$ & $6(50 \%)$ \\
\hline Caucasian & $13(20 \%)$ & $11(20 \%)$ & $2(17 \%)$ \\
\hline Asian & & &
\end{tabular}

\begin{tabular}{|l|l|l|l|}
\hline \multicolumn{3}{|l|}{ Smoker } \\
\hline Yes & $32(48 \%)$ & $28(51 \%)$ & $4(33 \%)$ \\
\hline DM & $39(59 \%)$ & $28(52 \%)$ & $11(92 \%)$ \\
\hline Yes
\end{tabular}

Table 1: General demographics.

A univariate logistical regression was used to determine if there is a relationship between race, smoking and diabetes mellitus in death from necrotizing fasciitis. There was no statistically significant difference in death/survival between Caucasian(s) and the two other categories (ATSI/Asian). Moreover, an overall chi square test, (also known as a Wald test) shows that there is no statistically significant relationship between Race and Death/Survival following Necrotising Fasciitis (chi2 $(2 \mathrm{df})=2.62, \mathrm{p}=0.2697) \quad($ Table 2). There was no statistically significant relationship between Survival/Death following Necrotising Fasciitis and Smoking $(\mathrm{z}=-1.14, \mathrm{p}=0.252)$ (Table 3).

\begin{tabular}{|l|l|l|l|l|l|l|}
\hline Death & $\begin{array}{l}\text { Odds } \\
\text { ratio }\end{array}$ & Std.Err. & $\mathbf{z}$ & $p>|z|$ & \multicolumn{2}{l|}{ 95\% Conf. Interval } \\
\hline \multicolumn{5}{|l|}{ Caucasian (reference) } \\
\hline Asian & 0.4242424 & 0.3862713 & -0.94 & 0.346 & 0.0712193 & 2.527146 \\
\hline ATSI & 0.3218391 & 0.232656 & -0.157 & 0.117 & 0.0780385 & 1.327298 \\
\hline _Cons & 0.4285714 & 0.2091214 & -1.74 & 0.082 & 0.1646946 & 1.115237 \\
\hline
\end{tabular}

Table 2: Univariate logistical regression on race.

\begin{tabular}{|l|l|l|l|l|l|l|}
\hline Death & Odds ratio & Std.Err. & $\mathbf{Z}$ & $\mathbf{P}>|\mathbf{z}|$ & $\mathbf{9 5 \%}$ conf. & Interval \\
\hline Yes & 0.4642857 & 0.311167 & -1.14 & 0.252 & 0.124826 & 1.7266893 \\
\hline _Cons & 0.3076923 & 0.1244012 & -2.92 & 0.004 & 0.1393069 & 0.6796114 \\
\hline
\end{tabular}

Table 3: Univariate logistical regression on smoking.

There was however a statistically significant relationship between Survival/Death following Necrotising Fasciitis and DM $(z=2.15$, $\mathrm{p}=0.031$ ). Patients in this cohort who suffer from DM are approximately 10 times more likely to die as a result of Necrotising Fasciitis than patients who do not suffer from DM (Table 4).

\begin{tabular}{|l|l|l|l|l|l|l|}
\hline Death & Odds ratio & Std.Err. & $\mathbf{Z}$ & $\mathbf{P}>|\mathbf{z}|$ & \multicolumn{2}{|l|}{$\mathbf{9 5 \%}$ Conf. Interval } \\
\hline Yes & 10.21429 & 11.02521 & 2.15 & 0.031 & 1.231484 & 84.72026 \\
\hline _Cons & 0.0384615 & 0.0391942 & $\begin{array}{l}-3.2 \\
0\end{array}$ & 0.001 & 0.00521193 & 0.2834282 \\
\hline
\end{tabular}

Table 4: Univariate logistical regression on Diabetes mellitus.

\section{Disease factors}

The precipitant of necrotising fasciitis in the majority of the patients was spontaneous (32 patients (48\%)). Following this, minimal trauma was the precipitant in 17 patients $(26 \%)$ and post-operative was the precipitant in 7 patients $(11 \%)$. A total of 10 cases were attributed to "other", which included necrotising fasciitis as a consequence of 
Citation: Vishnoi V, Chiam HC, Liebenberg P (2018) Necrotizing Fasciitis: A Review of Outcomes from Necrotizing Fasciitis in Regional Far North Queensland. J Trop Dis 6: 285. doi:10.4172/2329-891X.1000285

Page 3 of 6

diabetic foot ulcers, foreign bodies and one case secondary to an ultralow rectal cancer.

The location of necrotizing fasciitis was mainly in the legs, thigh and perineum. "Other" locations included upper body, torso and back. The average time to surgery overall was 40 hours, however there was a large standard deviation. The overall variance in data can be attributed to the large distances between referral hospitals in far north Queensland (Table 5).

\begin{tabular}{|l|l|l|l|}
\hline & $\begin{array}{l}\text { Whole group } \\
(\mathbf{n = 6 6 )}\end{array}$ & $\begin{array}{l}\text { Survivors } \\
(\mathbf{n = 5 4 )}\end{array}$ & Deceased (n=12) \\
\hline Precipitant & $32(48 \%)$ & $26(48 \%)$ & $6(50 \%)$ \\
\hline Spontaneous & $7(11 \%)$ & $6(11 \%)$ & $1(8 \%)$ \\
\hline Post op & $17(26 \%)$ & $15(28 \%)$ & $2(17 \%)$ \\
\hline Trauma & $10(15 \%)$ & $7(13 \%)$ & $3(25 \%)$ \\
\hline Other & $24(36 \%)$ & $19(35 \%)$ & $5(31 \%)$ \\
\hline Location & $8(12 \%)$ & $5(9 \%)$ & $3(25 \%)$ \\
\hline Leg & $18(27 \%)$ & $16(30 \%)$ & $2(17 \%)$ \\
\hline Thigh & $16(24 \%)$ & $14(26 \%)$ & $2(17 \%)$ \\
\hline Perineum/Genitalia & & \\
\hline Other & $39.2 \pm 96.28$ & $74.28 \pm 100.18$ & $32.06 \pm 94.48$ \\
\hline Time to Surgery & \multicolumn{3}{|l}{} \\
\hline (Hours) &
\end{tabular}

Table 5: Disease factors.

A univariate logistical regression showed that there is no statistically significant difference in death/survival between the reference level (Spontaneous) and the other three categories. Moreover, an overall chi square test, shows that there is no statistically significant relationship between Precipitant and Death/Survival following Necrotising Fasciitis [chi2 (3df) $=1.43, \mathrm{p}=0.6994$ ] (Table 6).

\begin{tabular}{|l|l|l|l|l|l|l|l|}
\hline Death & Odds ratio & Std.Err. & $z$ & $p>|z|$ & \multicolumn{5}{l|}{ 95\% Conf. Interval } \\
\hline \multicolumn{6}{|l|}{ Spontaneous (reference) } \\
\hline Post op & 0.7222222 & 0.845893 & -0.28 & 0.781 & 0.07277298 & 7.171816 \\
\hline Trauma & 0.5777778 & 0.5075885 & -0.62 & 0.532 & 0.1032677 & 3.232639 \\
\hline Other & 1.857143 & 1.532923 & 0.75 & 0.453 & 0.03683378 & 9.363632 \\
\hline Cons & 0.2307692 & 0.1045179 & -3.24 & 0.001 & 0.094986 & 0.5606558 \\
\hline
\end{tabular}

Table 6: Univariate logistical regression on precipitant.

This was also demonstrated with reference to location of NF. There was no statistically significant difference in death/survival between the reference level (Leg) and the other three categories. Moreover, an overall chi square test, shows that there is no statistically significant relationship between Location of lesion and Death/Survival following Necrotising Fasciitis (chi2(3df) $=1.43, \quad \mathrm{p}=0.6994) \quad$ (Table 7).
Furthermore, no statistical significance was found in relation to time to surgery and death from necrotizing fasciitis $(\mathrm{z}=-1.22, \mathrm{p}=0.223)$ (Table $8)$, which is a relevant finding for a regional referral centre.

\begin{tabular}{|l|l|l|l|l|l|l|}
\hline Death & $\begin{array}{l}\text { Odds } \\
\text { ratio }\end{array}$ & Std.Err. & $\mathbf{Z}$ & $\begin{array}{l}\mathbf{P}>\mid \\
\mathbf{z} \mid\end{array}$ & \multicolumn{2}{|l|}{$\mathbf{9 5}$ Conf. Interval } \\
\hline \multicolumn{7}{|l|}{ Leg (Reference) } \\
\hline Thigh & $\begin{array}{l}0.428571 \\
4\end{array}$ & $\begin{array}{l}0.500072 \\
83\end{array}$ & $\begin{array}{l}-0 . \\
73\end{array}$ & $\begin{array}{l}0.46 \\
8\end{array}$ & $\begin{array}{l}0.043440 \\
18\end{array}$ & 4.231928 \\
\hline $\begin{array}{l}\text { Genitalia/ } \\
\text { Perineum }\end{array}$ & 0.6 & $\begin{array}{l}0.473286 \\
4\end{array}$ & $\begin{array}{l}-0 . \\
65\end{array}$ & $\begin{array}{l}0.51 \\
7\end{array}$ & 0.127854 & 2.815711 \\
\hline Other & $\begin{array}{l}0.428571 \\
4\end{array}$ & $\begin{array}{l}0.381801 \\
8\end{array}$ & $\begin{array}{l}-0 . \\
95\end{array}$ & $\begin{array}{l}0.34 \\
2\end{array}$ & $\begin{array}{l}0.074767 \\
5\end{array}$ & 2.456596 \\
\hline Cons & $\begin{array}{l}0.333333 \\
3\end{array}$ & $\begin{array}{l}0.157134 \\
8\end{array}$ & $\begin{array}{l}-2 . \\
33\end{array}$ & $\begin{array}{l}0.02 \\
0\end{array}$ & $\begin{array}{l}0.132317 \\
9\end{array}$ & $\begin{array}{l}0.839728 \\
7\end{array}$ \\
\hline
\end{tabular}

Table 7: Univariate logistical regression on location.

\begin{tabular}{|l|l|l|l|l|l|l|}
\hline Death & $\begin{array}{l}\text { Odds } \\
\text { Ratio }\end{array}$ & Std.Err. & $\mathbf{Z}$ & $\mathbf{P}>|\mathbf{z}|$ & \multicolumn{2}{|l|}{ 95\% Conf. Interval } \\
\hline $\begin{array}{l}\text { TTS } \\
\text { (hours) }\end{array}$ & 1.000057 & 0.0000465 & 1.22 & 0.223 & 0.9999655 & 1.000148 \\
\hline _Cons & 0.1725939 & 0.0637657 & -4.76 & 0.000 & 0.0836652 & 0.3560463 \\
\hline
\end{tabular}

Table 8: Univariate logistical regression on time to surgery.

\section{Microbiology}

Out of the 66 patients with NF, 64 had confirmed causative microbes on microscopy, culture and sensitivities. Mixed growth (polymicrobial) growth was the most common in the overall cohort, with a total of 22 patients (33.3\%), followed closely by 20 patients with Streptococcus (30.30\%). Streptococcus species included, Group A Streptococcus, Group B streptococcus, Streptococcus milleri, and Streptococcus Viridians. The third largest group was classified as "other", with a total of 17 patients $(25.76 \%)$. This group included rarer bacterial species such as Vibrio, Aeromonas and Clostridium, which are common in tropical environments such as Cairns. Staphylococcus (MSSA/MRSA) in isolation was the rarest cause with a total of 7 patients $(10.61 \%)$ (Table 9$)$.

\begin{tabular}{|c|c|c|c|}
\hline Culture & Whole $(n=66)$ & Survivors $(n=54)$ & $\begin{array}{l}\text { Deceased } \\
\left(n=11^{*}\right)\end{array}$ \\
\hline Mixed Growth & $22(33.3 \%)$ & 20 & 2 \\
\hline $\begin{array}{l}\text { Streptococcus } \\
\text { (GAS, Milleri, } \\
\text { GBS, Anginosus) }\end{array}$ & $20(30.30 \%)$ & 16 & 4 \\
\hline $\begin{array}{l}\text { Staphylococcus } \\
\text { (MSSA/MRSA) }\end{array}$ & $7(10.61 \%)$ & 3 & 4 \\
\hline Other & $17(25.76 \%)$ & 16 & 1 \\
\hline \multicolumn{4}{|c|}{$\begin{array}{l}\text { Other includes: Vibrio, Saksenaea vasiformis ,Aeromonas, Clostridiu } \\
\text { growth. } \\
\text { "one microbiology culture not available on a deceased patient, hence } n=11\end{array}$} \\
\hline
\end{tabular}

Table 9: Summary of culture. 
Page 4 of 6

A univariate logistical regression demonstrated that there is a statistically significant difference in death/survival between an isolated Staphylococcus infection and the three other culture types. The coefficient from this regression suggests that people with an isolated Staphylococcus culture are more likely to die that those with Mixed or Streptococcus cultures (Table 10).

\begin{tabular}{|c|c|c|c|c|c|c|}
\hline Death & $\begin{array}{l}\text { Odds } \\
\text { Ratio }\end{array}$ & Std.Err. & $z$ & $p>|z|$ & \multicolumn{2}{|c|}{ 95\% Conf. Interval } \\
\hline \multicolumn{7}{|c|}{ Staphylococcus ( reference ) } \\
\hline $\begin{array}{l}\text { Mixed } \\
\text { Growth }\end{array}$ & 0.075 & $\begin{array}{l}0.079843 \\
6\end{array}$ & $\begin{array}{l}-2.4 \\
3\end{array}$ & 0.015 & $\begin{array}{l}0.009308 \\
7\end{array}$ & $\begin{array}{l}0.604274 \\
9\end{array}$ \\
\hline Streptococcus & 0.132353 & $\begin{array}{l}0.120720 \\
9\end{array}$ & $\begin{array}{l}-2.0 \\
5\end{array}$ & 0.041 & $\begin{array}{l}0.019099 \\
8\end{array}$ & $\begin{array}{l}0.917147 \\
2\end{array}$ \\
\hline Other & $\begin{array}{l}0.160714 \\
3\end{array}$ & $\begin{array}{l}0.159754 \\
8\end{array}$ & $\begin{array}{l}-1.8 \\
4\end{array}$ & 0.066 & $\begin{array}{l}0.022905 \\
2\end{array}$ & 1.12765 \\
\hline _Cons & 1.333333 & 1.01835 & 0.38 & 0.706 & $\begin{array}{l}0.298416 \\
5\end{array}$ & 5.957371 \\
\hline
\end{tabular}

Table 10: Univariate logistical regression, demonstrating an increased likelihood of mortality with an isolated Staphylococcus necrotizing fasciitis.

\section{Complications}

As previously discussed the overall intensive care admission rate was $74 \%$, with an overall mortality of $18 \%$. A total of 34 patients $(52 \%)$ required inotropic support due to septic shock, with a further subset of patients demonstrating evidence of multi-organ failure. The use of inotropic support carried a higher risk of mortality $(\mathrm{p}=0.026)$. The presence of acute renal failure on initial presentation (definition derived from the RIFLE criteria), was present in 22 patients overall (33.3\%), and in $75 \%$ of patients who eventually died from necrotizing fasciitis (Table 11). A univariate analysis showed that there is a statistically significant relationship between Survival/Death following Necrotising Fasciitis and acute renal failure $(\mathrm{z}=-3.04, \mathrm{p}=0.002)$ (Table 12).

\begin{tabular}{|l|l|l|l|}
\hline & $\begin{array}{l}\text { Whole group } \\
(\mathbf{n = 6 6 )}\end{array}$ & Survivors $(\mathbf{n}=\mathbf{5 4})$ & Deceased $(\mathbf{n}=\mathbf{1 2})$ \\
\hline Yes & $22(33.3 \%)$ & $13(24 \%)$ & $9(75 \%)$ \\
\hline No & $44(66.7 \%)$ & $41(76 \%)$ & $3(25 \%)$ \\
\hline
\end{tabular}

Table 11: Acute renal failure.

\begin{tabular}{|l|l|l|l|l|l|l|}
\hline Death & $\begin{array}{l}\text { Odds } \\
\text { Ratio }\end{array}$ & Std.Err. & $\mathbf{Z}$ & $\mathbf{p}>|\mathbf{z}|$ & \multicolumn{2}{|l|}{ 95\% Conf. Interval } \\
\hline Yes & 9.461535 & 6.989748 & 3.04 & 0.002 & 2.223991 & 40.25226 \\
\hline Cons & 0.0731708 & 0.0437634 & -4.37 & 0.000 & 0.0226586 & 0.2362877 \\
\hline
\end{tabular}

Table 12: Univariate logistical regression of acute renal failure.

\section{Multivariate analysis}

Following the statistical analysis of the relevant variables in the univariate analysis ( $p$ value $<0.05$ ) a stepwise Logistic Regression was used to further study the relationship between Survival/Death following Necrotising Fasciitis. Separate runs with forward and backwards elimination with an entry/exit level of $\mathrm{p}=0.05$ was performed. Both techniques yielded the same reduced model presented in Table 13.

The logistic regression coefficients in Table 13 show the increase (or decrease) in the odds ratio of the outcome (Death) for a one unit increase in the predictor variable. As an example, in the case of ARF, a one-unit change (going from $\mathrm{No}=0$ to $\mathrm{Yes}=1$ ) increases the chances of death due to Necrotising Fasciitis by a factor of $9(\mathrm{z}=2.46, \mathrm{p}=0.014)$.

$\mathrm{DM}$ is borderline significant $(\mathrm{z}=1.93, \mathrm{p}=0.054)$ but it was left in the model as it was significant in the univariate regressions and there is strong evidence in the literature pointing to a higher risk of death for DM sufferers who contract Necrotising Fasciitis.

For the cell cultures, this study suggests that people with an isolated Staphylococcus culture, run a higher risk of death than people with the other cell cultures observed in this study. All the p values for the 'decrease' in risk for Mixed, Streptococcus and Other in relation to Staphylococcus, are statistically significant.

\begin{tabular}{|c|c|c|c|c|c|c|}
\hline Death & $\begin{array}{l}\text { Odds } \\
\text { Ratio }\end{array}$ & Std.Err & $\mathbf{Z}$ & $P>|z|$ & \multicolumn{2}{|c|}{$95 \%$ Conf. Interval } \\
\hline \multicolumn{7}{|l|}{ DM } \\
\hline Yes & 11.1639 & 13.95437 & 1.93 & 0.054 & 0.963502 & 129.3539 \\
\hline \multicolumn{7}{|l|}{ ARF } \\
\hline Yes & 9.078005 & 8.131684 & 2.46 & 0.014 & 1.568631 & 52.53636 \\
\hline \multicolumn{7}{|c|}{ Staphylococcus (reference) } \\
\hline Mixed & 0.035571 & 0.054731 & -2.17 & 0.03 & 0.001743 & 0.725769 \\
\hline Streptococcus & 0.042785 & 0.06512 & -2.07 & 0.038 & 0.002166 & 0.844969 \\
\hline Other & 0.045096 & 0.069231 & -2.02 & 0.044 & 0.002225 & 0.913877 \\
\hline _Cons & 0.187398 & 0.243434 & -1.29 & 0.198 & 0.01469 & 2.390536 \\
\hline
\end{tabular}

Table 13: Multi-variate analysis.

\section{Discussion}

The aim of this review was to explore the factors that influence the overall outcomes in patients with Necrotizing fasciitis in regional Far North Queensland. This study specifically looked at patient demographic/co-morbidities, disease and logistical factors in necrotizing fasciitis. Certain unexpected trends were identified, which are discussed here. The overall mortality was $18 \%$, which is within the "normal" documented mortality rates in the current literature (16\%-34\%) [6,7].

Those at risk of NF and its complications are often co-morbid patients with diabetes mellitus, cardiovascular disease and peripheral vascular disease [8]. Our data has confirmed this, with the strongest risk factor in the cohort being diabetes mellitus (60\%). Furthermore, the likelihood of death following a diagnosis of necrotizing fasciitis was 10 times higher in those with diabetes mellitus; this trend is consistent with previous literature [9]. Interestingly, less than half the patient cohorts were smokers, with no statistically significant impact on mortality following a diagnosis of NF. This goes against current literature, as smoking is suggested to be a significant risk factor in contracting necrotizing fasciitis [10]. 
Page 5 of 6

A study in the United Sates demonstrated a higher incidence of NF in Hispanic, African American and Native Indian population; however increased mortality as a result of race was not apparent [11]. A similar trend was demonstrated in a retrospective review of cases of NF in New Zealand [12], amongst the Maori population. Our data was equivocal, with $50 \%$ of the cohort being ATSI, with no statistical impact on mortality. If there is a potential higher risk of mortality amongst indigenous populations, it is likely multi-factorial, influenced by co-morbidities, socio-economic status rather than just simply ethnicity. This warrants further investigation, in particular amongst Australia's ATSI population.

Early surgical debridement is the gold standard suggested treatment for necrotizing fasciitis, with clearly documented worse outcomes when surgery is delayed [13]. Far North Queensland is separated by large distances between major towns/cities. Taking this into consideration, over $50 \%$ of our cohorts were located outside of Cairns, requiring medical retrieval from rural medical centres. The delay in surgical intervention was apparent, with the average time to surgery being close to 2 days from diagnosis (40 hours). However, unexpectedly, this had no statistical impact in the overall mortality. A similar trend was identified in a retrospective review of NF at the Prince Alfred Hospital in Victoria. Their ten-year review demonstrated no statistical impact on mortality when surgical debridement was delayed $>24$ hours [14]. The lack of statistical significance in this review is explained by the following. Firstly, the small sample size of 66 patients gives rise to a high variability, and therefore bias. Secondly, the majority of patients had likely received broad spectrum antibiotics prior to arrival at Cairns base hospital, which may have halted disease progression. Lastly, the disease severity amongst patients needs to be considered. Some patients may have more localized disease without systemic toxicity and/or a greater ability to compensate. Regardless from our data, with death being the endpoint, time to surgery had no statistical impact, a relevant, but controversial finding.

NF is mainly caused by polymicrobial infection (type 1) [15], a finding reproduced in our data, with the most common culture demonstrating a polymicrobial infection (33.3\%). Other causative agents amongst the cohort included Streptococcus and Staphylococcus. Rarer causes such a Vibrio and Aeromonas were also identified however this is an expected finding for a tropical region [16]. Staphylococcus (6 cases of MSSA, 1 case of MRSA) in isolation was apparent in $10 \%$ of the cohort, carrying an increased risk of mortality which was statistically significant. This has been demonstrated in recent literature as an emerging cause carrying a high risk of mortality [17].

The location of NF in the majority was located in the lower limbs or thigh, with no overall statistical impact on death. In the literature approximately $\sim 50 \%$ of cases occur in the lower limbs [18], which is in keeping with our data. In this review, a spontaneous precipitant was apparent in the cases (48\%). "Spontaneous" is often difficult to conclude as patients may have easily had insect bites, minor trauma, scratches etc. which they may not disclose, or the signs may not be present due to the presence of the NF, which is a limitation of this retrospective review.

The majority of the cohort required an intensive care admission (74\%), with $54 \%$ overall also requiring inotropic support, fitting with natural disease progression. The literature suggests that an intensive care admission is associated with an increased risk of mortality following a diagnosis of necrotizing fasciitis [19]. Multiple studies have demonstrated the increase in mortality when acute renal failure is present following a diagnosis of necrotizing fasciitis [20-22], a finding reproduced in our review. The presence of acute renal failure (RIFLE criteria), carried nearly 9 times increased chance in mortality from necrotising fasciitis $(\mathrm{p}=0.014)$. Acute renal failure reflects multi-organ failure from the associated sepsis in NF. The insult is a combination of "pre-renal" injury from hypo-perfusion and "intrinsic renal" from acute tubular necrosis, all precipitated by the sepsis.

This review has identified trends consistent with current literature regarding necrotizing fasciitis. However, it does pose limitations given its retrospective nature. As with any retrospective review all the relevant factors cannot be studied in detail. Furthermore, the patient sample size is small, making valid conclusions difficult to draw. Moving forward, this study has identified the need to optimize patients' comorbidities such as diabetes mellitus and renal function, as both of these conditions have serious implications for patients with necrotizing fasciitis.

\section{Conclusion}

Overall this retrospective review reproduced known findings amongst the literature with risk factors such as diabetes mellitus, acute renal failure and mono-microbial infection with Staphylococcus aureus carrying a higher risk of mortality following a diagnosis of necrotizing fasciitis. Time to surgery and race (ATSI etc.) had no statistical impact in overall mortality which is a relevant finding Far North Queensland, a region vast in demographics and separated by large distances between communities. The retrospective nature of this review poses limitations; however, further prospective studies are required to improve outcomes in patients with necrotizing fasciitis.

\section{References}

1. Clebak KT, Malone MA (2018) Skin infections. Primary care: Clinics Office Practi 45: 433-454.

2. Puvanendran R, Meng Huey JC, Pasupathy S (2009) Necrotizing fasciitis. Can Fam Physician 55: 981-987.

3. Cainzoz M, Gonzalez-Rodriguez FJ (2007) Necrotizing soft tissue infections. Curr Opin Crit Care 13: 433-439.

4. Misiakos E, Bagis G, Patapis P, Sotiropoulos D, Kanavidis P, et al. (2014) Current concepts in the management of necrotizing fasciitis. Frontiers Surg 1: 1-10.

5. Health Q (2014) Profile cairns an hinterland hospital and health service. Queensland Government.

6. Shaikh N, El-Menyar A, Mudali IN, Tabeb A, Al-Thani H (2015) Clinical presentations and outcomes of necrotizing fasciitis in males and females over a 13-year period. Ann Med Surg 4: 355-360.

7. Martinschek A, Evers B, Lampl L, Gerngroß H, Schmidt R, et al. (2012) Prognostic aspects, survival rate, and predisposing risk factors in patients with fournier's gangrene and necrotizing soft tissue infections: evaluation of clinical outcome of 55 patients. Urologia Internationalis 89: 173-179.

8. Gupta Y CM, Pathak K, Jha R, Ghimire N, Mishra B, et al. (2016) Risk factors for necrtoizing fasciitis and its outcome at a tertiary care centre. J Ayub Med Coll Abbottabad 28: 680-682.

9. Cheng NC, Tai HC, Chang SC, Chang CH, Lai HS (2015) Necrotizing fasciitis in patients with diabetes mellitus: clinical characteristics and risk factors for mortality. BMC Infect Dis 15: 417.

10. Kalaivani V BV, Indumathi V (2013) Necrotising soft tissue infectionrisk factors for mortality. J Clin Diagn Res 7: 1662-166

11. Arif N, Yousfi S, Vinnard C (2015) Deaths from necrotizing fasciitis in the United States, 2003-2013. Epidemiol Infect 144: 1338-1344.

12. Das DK, Baker MG, Venugopal K (2012) Risk factors, microbiological findings and outcomes of necrotizing fasciitis in New Zealand: A retrospective chart review. BMC Infect Dis 2012;12. 
Citation: Vishnoi V, Chiam HC, Liebenberg P (2018) Necrotizing Fasciitis: A Review of Outcomes from Necrotizing Fasciitis in Regional Far North Queensland. J Trop Dis 6: 285. doi:10.4172/2329-891X.1000285

Page 6 of 6

13. TS B (1995) Necrotizing fasciitis-The hazard of delay. J R Soc Med 88 342-343.

14. Proud D, Bruscino Raiola F, Holden D, Paul E, Capstick R, et al. (2014) Are we getting necrotizing soft tissue infections right? A 10-year review. ANZ J Surg 84: 468-472.

15. Krieg A, Rohrborn A, Schulte J, Schubert D, Poll W, et al. Necrotizing fasciitis: Microbiological characteristics and predictors of postoperative outcome. Euro J Med Res 14: 30-36.

16. Park KH, Jung SI, Jung YS, Shin JH, Hwang JH (2009) Marine bacteria as a leading cause of necrotizing fasciitis in coastal areas of South Korea. Am J Trop Med Hyg 80: 646-650.

17. Cheng N WJ, Chang SC, Tai HC, Tang YB (2011) Necrotizing fasciitis caused by Stapylococcus aureus: The emergency of methicillin-resistan strains. Ann Plastic Surg 67: 632-636.
18. Bosshardt TH, Organ C (1996) Necrotizing soft tissue infections. Arch Surg 131: 846-854.

19. Shen HN, Lu CL (2010) Skin and soft tissue infections in hospitalized and critically ill patients: A nationwide population-based study. BMC Infect Dis 10: 151 .

20. Bair MJ, Chi H, Wang WS, Hsiao YC, Chiang RA, et al. (2009) Necrotizing fasciitis in southeast Taiwan: Clinical features, microbiology and prognosis. Int J Infect Dis 13: 255-260.

21. Elliott DC, Kufera JA, Myers RAM (1996) Necrotizing soft tissue infections: Risk factors for mortality and strategies for management. Ann Surg 224: 672-683.

22. Khamnuam P, Chongruksut W, Jearwattanakanok K, Patumanon J, Yodluangfun S, et al. (2015) Necrotising fasciitis: Risk factors of mortality. Risk Manag Healthc Policy 8: 1-7. 